\section{Effects of symbolic modeling on the syntactical productions of retardates ${ }^{\prime}$}

RICHARD D. ODOM, ${ }^{2}$ ROBERT $M$. LIEBERT, and LUIS E. FERNANDEZ, Vanderbilt University, Nashville, Tenn. 37203

The effects of symbolic modeling of syntactical constructions on the subsequent language productions of retarded children were assessed. As anticipated, the modeling groups showed greater production of specific, relevant constructions during training than no-model control Ss who were also rewarded for such constructions. Three weeks following the initial task, a posttest indicated that the effect of modeling was durable.

The present experiment investigated the effects of hearing a tape-recording of syntactical constructions on the subsequent sentence productions of educably mentally retarded children. The recording was of a model producing sentences, some of which contained prepositional phrases, which we re of the type (preposition-article-noun) used in studies investigating the effects of live modeling on the syntax of normally intelligent children (Liebert, Odom, Hill, \& Huff, 1969; Odom, Liebert, \& Hill, 1968).

In addition to examining the role of modeling sentences which did or did not contain the relevant construction, the design also included the variable of vicarious reward. It was assumed that all of these variables would enhance the S's ability to discriminate, and subsequently to use, the relevant constructions (prepositional phrases). Finally, since the durability of imitative learning has been examined in relatively few studies, a follow-up test was employed.

\section{METHOD}

The Ss were 30 children, 15 boys and 15 girls, between the ages of 14.1 and 15.9 years, who scored between 75 and 85 on the Peabody picture vocabulary test $(1959)$. $^{3}$ The same $E$, an adult female, served

Table 1

Mean Number of Sentences with Prepositional Phrases Produced by Children in All Groups After Training and During Follow-up

\begin{tabular}{|c|c|c|c|c|c|c|}
\hline \multirow{2}{*}{\multicolumn{2}{|c|}{ After Training }} & \multicolumn{5}{|c|}{ Follow-up } \\
\hline & & \multicolumn{2}{|c|}{ Order $A B$} & \multicolumn{2}{|c|}{ Order BA } & \multirow{2}{*}{$\begin{array}{l}\text { Follow-up } \\
\text { Combined }\end{array}$} \\
\hline & List B & List A & List B & List A & List B & \\
\hline 20 No Reward & 8.67 & 10.00 & 10.67 & 6.67 & 5.33 & 8.17 \\
\hline 20 Reward & 6.17 & 7.33 & 3.67 & 7.67 & 10.33 & 7.25 \\
\hline 15 No Reward & 6.00 & 10.67 & 7.00 & 6.00 & 3.67 & 6.84 \\
\hline 15 Reward & 5.87 & 7.00 & 5.33 & 6.67 & 4.33 & 5.83 \\
\hline Control & 2.83 & 5.00 & 3.00 & 5.67 & 5.00 & 4.67 \\
\hline Combined & & 8.00 & 5.93 & 6.54 & 5.73 & \\
\hline
\end{tabular}

them. All sentences containing prepositional phrases of the form preposition-article-noun were rewarded with praise and a token. Three weeks later, half of the children in each of the five original groups were presented the two lists of 15 stimulus nouns in the original order (List $A$ followed by List B), and the other half were presented the lists in reverse order (List B followed by List A). The stimulus words were presented with no additional training or instruction.

\section{RESULTS AND DISCUSSION}

A one-way analysis of variance was performed on the number of sentences with prepositional constructions of the form modeled. The results revealed that the five groups did not differ initially $(\mathrm{F}=1.20)$.

Table 1 presents the mean number of sentences containing the prepositional construction produced by each group during training and follow-up. A one-way analysis of variance was performed on the number of sentences with prepositional constructions made by the five groups during training. This analysis revealed significant differences regarding group performance $(F=5.46$, $\mathrm{df}=4 / 25, \mathrm{p}<.01$ ). Additionally, when each of the means of the experimental groups is compared with that of the control using Dunnett's procedure, all of the differences were found to be significant. However, a 2 (vicarious reward) by 2 (absence of relevant construction) analysis of the four modeling groups' performance yielded no significant main or interaction effects.

A 5 (group) by 2 (list sequence) by 2 (list) analysis of variance with repeated measures on the last factor was conducted for the 3-week follow-up. This analysis revealed that the groups still differed regarding production of modeled prepositional constructions $(F=3.36, \quad d f=4 / 20$, $p<.01$ ), and that List $A$ was more conducive to the production of such constructions than List $B \quad(F=8.93$, $\mathrm{df}=1 / 20, \quad \mathrm{p}<.01)$. The only other significant effect, a Groups by Sequence interaction $(F=5.30, \mathrm{df}=4 / 20, p<.01)$, appears to have occurred because the control group and the vicarious reward group that heard 20 sentences performed better when List B preceded List A, whereas the reverse was true for the remaining groups.

The results of this experiment provide initial evidence that a very brief period of symbolic modeling can increase children's production of certain grammatical constructions. Thus, the data indicate that these mildly retarded children were able to identify a rule for generating prepositional phrases, and that after 3 weeks, they were still able to recall and to utilize this rule. Clearly, however, the effects of vicarious reward and other discriminative cues in such 
learning situations with retardates require further clarification. A program of research is under way to refine these procedures and, thus, establish efficient techniques for modifying the language usage of retarded children.

\section{REFERENCES}

LIEBERT, R. M., ODOM, R. D., HILL, J. H., \& HUFF, R. L. Effects of age and rule familiarity on the production of modeled language constructions. Developmental Psychology, $1969,1,108-112$
ODOM, R. D., LIEBERT, R. M., \& HILL, J. H. The effects of modeling cues, reward, and at tentional set on the production of grammatical and ungrammatical syntactic constructions. Journal of Experimental Child Psychology, 1968, 6, 131-140.

$$
\text { NOTES }
$$

1. The study was supported by Department of Health, Education, and Welfare Grant No. RD-2952-S from the Social and Rehabilitation Service.

2. The contributions of the first two authors were equal.

3. We wish to express our thanks to the staff of the Williamson County schools, without whose cooperation this study would not have been possible. opposite may be true. That is, those who are in control of their environment tend to be less risky than those who are not in control.

Consider, for example, current developments in higher education. Who is it today that is more anxious to make changes in the traditional methods? Is it the "Establishment," the administrators in control of the system? Or is it the students who do not feel that they have enough say in controlling their educational environment? Similarly, in business, it typically appears to be the younger executives, more than the senior executives in control of the company, who are willing to innovate, to try out new products and new ideas. And as young executives become senior executives, as they move onto the board of directors, and as they gain more control, do they then tend to become more conservative or more risky? Observations indicate that they usually become more conservative.

There are other areas in which people who are not in control of their environment appear more willing to take risks than those who are in control, e.g., areas of politics, war, and competitive sports. Since we can observe this phenomenon so often in real life, why do many laboratory studies of risk taking indicate that more risk is taken by those who feel that they are in control of their environment?

The conditions producing risky decision making in the kinds of real-world situations described above may differ from the psychological laboratory studies in several ways: (1) most such real-world situations involve conflict-the people not in control want to gain control; (2) potential loss and gain is likely to be greater in the real world; (3) there is probably greater personal involvement of the decision makers in the real world (since careers, fortunes, and lives are of ten at stake); and (4) outcomes of decisions in the real world are more complex, based on interacting multiple determinants rather than on a single determinant (such as the roll of a die).

Unfortunately, it is difficult, if not impossible, to subject real-world decision making to experimental control. How, then, can we resolve the dilemma? How can we study risk taking and perceived control as they relate to real-world situations? It may be helpful to employ an experimental simulation setting with "real-world-like" components and experimental variable control. Although it is not possible to introduce the extent of gain and loss found in the real world into a simulation, it has been frequently demonstrated that the participants in such a simulation experience considerable involvement. In addition, they are faced with a more complex environment than most laboratory studies on risk taking provide; and, in the simulation used in this 